\title{
Caffeine as a Probable Factor for Increased Risk of OAB Development in Elderly People
}

\author{
Kirill V. Kosilova ${ }^{\mathrm{a}}$ Sergay A. Loparev ${ }^{\mathrm{b}} \quad$ Marina A. Ivanovskaya $^{c} \quad$ Liliya V. Kosilova $^{\mathrm{d}}$

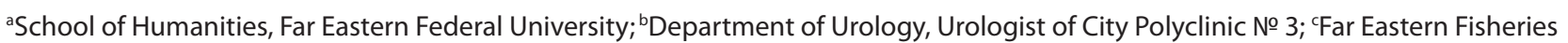 \\ University; ${ }^{\text {dDepartment }}$ of the Functional Methods of Examination, Med. Association № 2 of Vladivostok-sity, Vladivostok, Russia
}

\section{Key Words \\ Antimuscarinic • Elderly patients • Overactive bladder}

\section{Abstract}

Objective: This study was conducted to compare overactive bladder $(O A B)$ prevalence among people greater than 60 years of age who intake various doses of caffeine, as well as those who abstain from caffeine. Patients and Methods: A randomized observational study was carried out in Vladivostok Gerontological Hospital. A total of 1,098 retired people greater than 60 years of age ( 659 women and 439 men, average age 67.1 years) took part in the study. They were admitted to the in-patient department with the purpose of annual physical examination performed in accordance with the order of the Ministry of Public Health of the Russian Federation. People over age 60, who at the moment of examination were in satisfactory health condition, were included into the study. People in which OAB had been detected or who used to take antimuscarinic were excluded from the study. Assessment tools for examining the patients' lower urinary tract condition were as follows: OAB-q SF, urination diaries, and uroflowmetry. Results: In the course of the experiment conducted, we found that 1/3 of people, both men and women greater than 60 years of age, who did not previously seek medical advice due to urination troubles, had symptoms of detrusor overactivity. These symptoms were moderate and did not bother patients too much in most cases

\section{KARGER}

Fax +4161306 1234

E-Mail karger@karger.ch

www.karger.com
(C) 2015 S. Karger AG, Basel

$1015-9770 / 15 / 0093-0124 \$ 38.00 / 0$

Accessible online at:

www.karger.com/cur
(63.4\%). It was also found that most patients consumed no more than $300 \mathrm{mg}$ caffeine with beverages per day, with $30 \%$ and $10 \%$ of patients suffering from $O A B$ or severe detrusor overactivity, respectively. At the same time, almost $50 \%$ of patients taking more than $300 \mathrm{mg}$ of caffeine per day suffer from OAB. Conclusion: $48.1 \%$ of people over 60 years of age suffering from overactive detrusor symptoms consume greater than $300 \mathrm{mg}$ caffeine daily, which is significantly higher than that of their peers who do not intake excessive amounts of caffeine.

Copyright $\odot 2015$ S. Karger AG, Basel

\section{Introduction}

The prevalence of overactive bladder (OAB) in most populations is quite high and tends to increase among elderly and senile patients for both genders [1-3]. The frequency of $\mathrm{OAB}$ symptom occurrence differs slightly depending on gender, race, and age of examined people, ranging 8-30\% [4].

To date, extensive researche has considered the issue of $\mathrm{OAB}$ treatment as urgent and requiring further studies $[5,6]$. The development of OAB symptoms is associated with malfunction of some muscarinic receptors (particularly, $M_{2}$ and $M_{3}$ receptors), 'afference noise' occurrence 


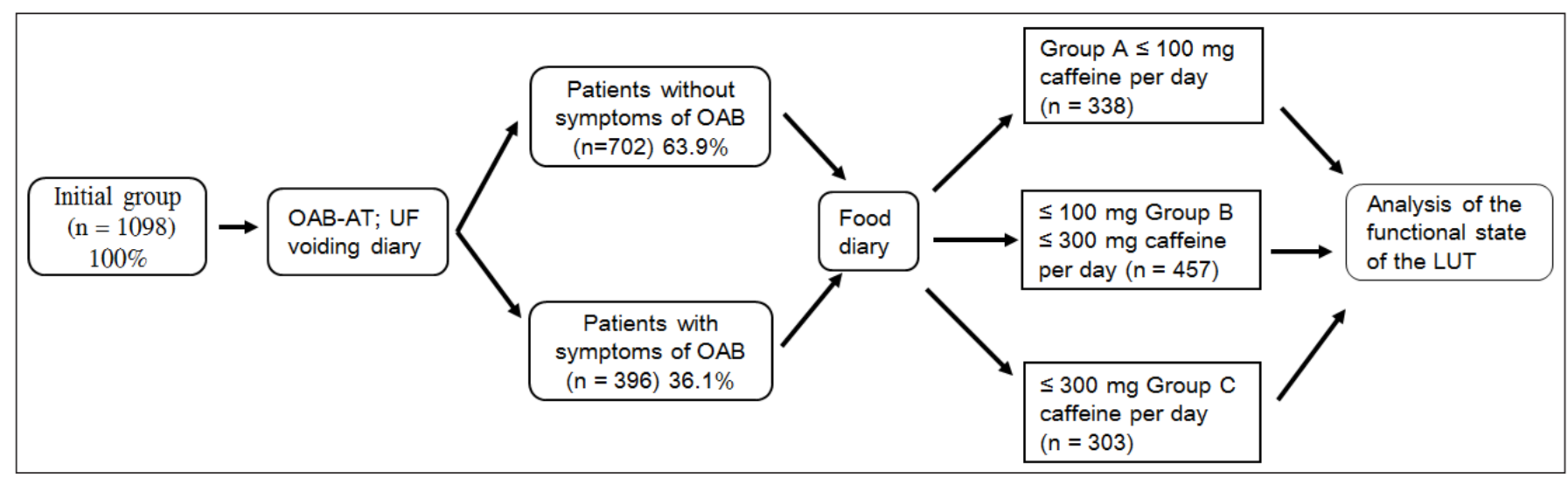

Fig. 1. The algorithm of distribution of the group and examination. OAB-AT (OAB Awareness Tool) - questionnaire to assess the symptoms of overactive bladder; UF uroflowmetry.

in detrusor's conducting system, pelvic floor muscle weakness in women, formation of initial prostatic hyperplasia in men, and also chronic inflammatory processes in lower urinary tracts symptoms (LUTS) [7-12]. Several interesting studies that support previous claims regarding disorders of some parts of the spinal cord have also been recently published. For example, there have been reports regarding brain stem reticular formation pathology as a possible cause of idiopathic OAB formation. According to another study, vascular disorders of subcortical nerve centers may be one of the causes of OAB symptom occurrence [13].

The effect of caffeine on various levels of nervous system organization has been studied quite thoroughly [14-16]. Some research demonstrates the possible effect of excessive caffeine dose on detrusor function [17]. In particular, it is reported that caffeine consumption increases the activity of sensory input and promotes the formation of overactive detrusor in mice [18]. Considering the great number of these studies, it is likely that caffeine may affect the human bladder similarly $[19,20]$. Yet, a number of studies cast doubt on the direct effect of caffeine on OAB symptom occurrence in healthy people. There is also no widely recognized understanding of what constitutes excessive levels of caffeine that may increase the risk of OAB development [21].

Considering the afformentioned studies, we compared $\mathrm{OAB}$ prevalence among people over 60 years of age who consume various caffeine doses as well as thoes who do not use caffeine in their diet. We hypothesize that excessive caffeine dose might promote the formation of $\mathrm{OAB}$ symptoms in people over 60 years of age.

\section{Patients and Methods}

The study was carried out in Vladivostok Gerontological Hospital from October 2011 to October 2013. A total of 1,098 people greater than 60 years of age (659 women and 439 men, average age 67.1 years old) that were admitted to the in-patient department for annual physical examination in accordance with the order of the Ministry of Public Health of the Russian Federation took part in the study. The patients were assigned into groups in a double-blinded and randomized study: Group A: not taking caffeine or taking $\leq 100 \mathrm{mg} / \mathrm{d}$ caffeine $(\leq 1.5 \mathrm{mg} / \mathrm{kg}$ ) (1 cup of coffee or 2 cups of tea or less), Group B: taking 100-300 mg/d caffeine, and Group C: taking $\geq 300 \mathrm{mg} / \mathrm{d}$ caffeine.

People with diagnosed OAB or taking antimuscarinic were excluded from the study. The same applied to all people who had relapses of chronic diseases. Patients who had been consuming moderate or large amounts of alcohol for a year prior to the examination (i.e. more than $24 \mathrm{~g} / \mathrm{d}$ ethanol for men and $12 \mathrm{~g} / \mathrm{d}$ for women, respectively); smokers who smoke more than 10 cigarettes per day, and also people who used to take psychoactive substances or diuretics, or used to consume excessive amounts of liquid, were excluded during assignment to the groups.

Assessment tools for examination of the patients' lower urinary tract condition were as follows:

- OAB-Awareness Tool (OAB-AT) questionnaire (OAB signs at the sum higher 8 points) [22, 23].

- bladder diaries with registration of urination volumes, number of urge episodes (UE), incontinence episodes (IE), and episodes of nighttime urination (ENU) [24, 25].

- uroflowmetry with registration of average and maximum flow rate $\left.\left(\mathrm{Q}_{\text {aver }}, \mathrm{Q}_{\max }\right)\right)[26,27]$.

$\mathrm{OAB}$ symptoms were considered severe if the sum was more than 20 points according to the OAB-AT questionnaire and IE $\geq$ 3 per day (urination diary). A number of OAB-q points $\geq 8$ was a diagnostic standard for establishing diagnosis [28, 29].

The amount of caffeine consumed daily was estimated using the corresponding questionnaire $[17,19,20]$. As a rule, maximum daily caffeine dose recommended by manufacturers for therapeu- 


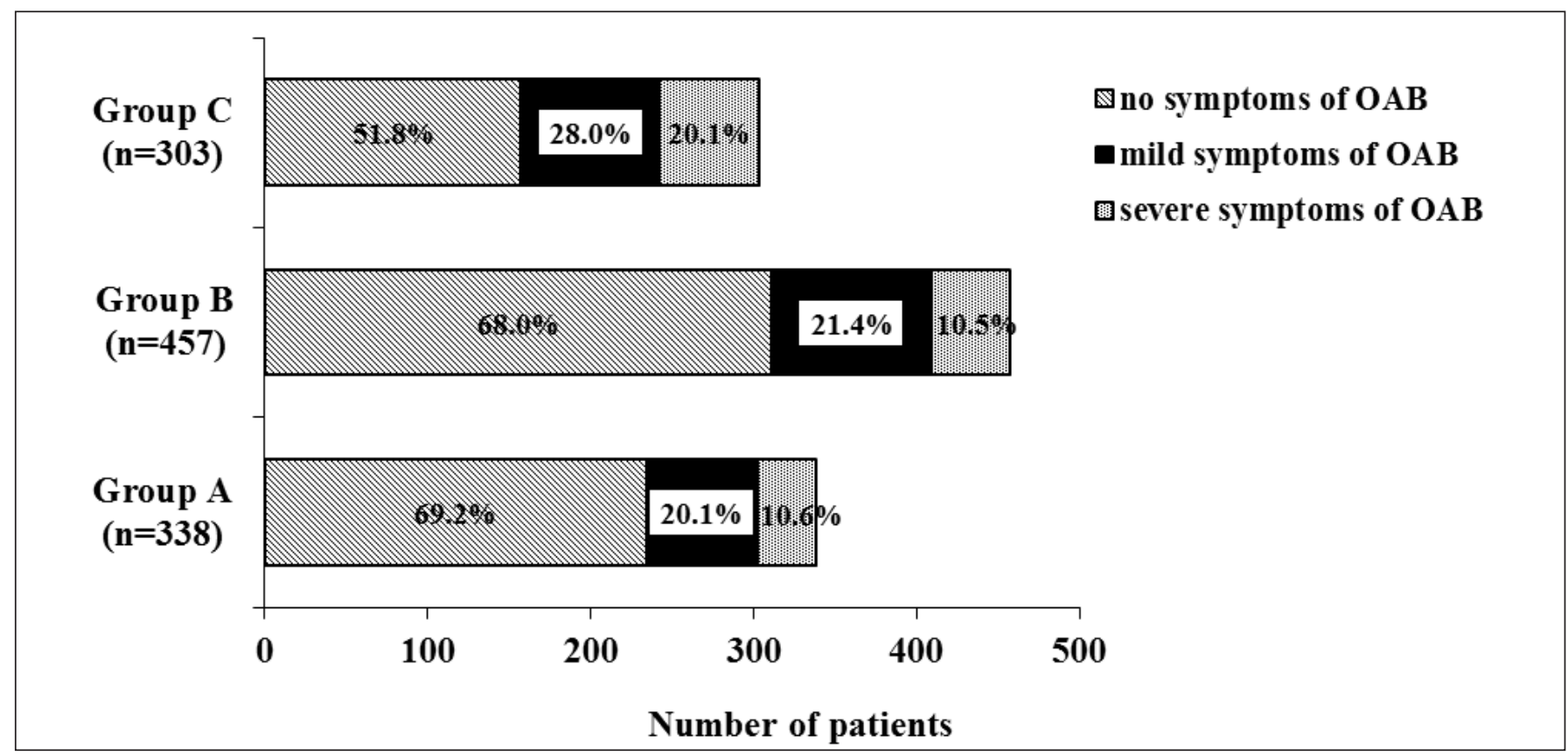

Fig. 2. The proportion of patients with a variety of state LUT in Group A ( $\leq 100 \mathrm{mg} / \mathrm{d}$ caffeine), Group B ( $>100 \mathrm{mg} / \mathrm{d}$ and $\leq 300 \mathrm{mg} / \mathrm{d}$ caffeine), and Group C $(<300 \mathrm{mg} / \mathrm{d}$ caffeine).

tic purposes does not exceed $300 \mathrm{mg}$ [30]. Indicative caffeine content in a cup of ground coffee is $85-150 \mathrm{mg}$, instant coffee: $60-75$ $\mathrm{mg}$, and tea and cola: about $40 \mathrm{mg}$. We certainly were aware that there is a great number of coffee and tea varieties and that the caffeine content in each may vary. In addition, not all patients included in each specific group consumed the same variety of coffee or tea drink during the research or adhered to the specific amount of caffeine-containing products. However, according to the data of some researchers, caffeine content in more than $90 \%$ of all coffee and tea varieties is within a certain range [31, 32]. Therefore, aware of the difficulty connected with accurately calculating the amount of caffeine, we used the range's median value for the caffeine content in a cup of ground or instant coffee or tea. The patients were informed about caffeine presence in chocolate and the necessity to include the information about chocolate intake into the diary. In addition, all patients informed the researchers that caffeine-containing cold beverages were of no interest to them and were not consumed (at least on regular basis).

All participants of the experiment were asked to indicate the quantity of their daily consumption of the above-mentioned products. Men and women who reported their addiction to a certain amount of caffeine-containing drinks for at least one year were selected for the groups.

Study design is presented in fig. 1. The research design was approved by the Ethics Committee of Far-Eastern Federal University. The information acquired was processed and prepared for further analysis using JMP SAS Statistical Discovery 8.0.2 (SAS Institute, Cary, NC, USA) software. Wilcoxon Criteria was used for comparing data in the groups. Values of standard deviation $\mathrm{p}<$ 0.05 were considered statistically significant.

\section{Results}

As table 1 shows, the occurrence rate for cardiovascular pathology is the highest $(51.5 \%)$, and the numbers of patients suffering from respiratory and gastrointestinal diseases (28.8\% and $24.4 \%$ respectively) is also rather high. In general, the percentage of various diseases in the groups correlates with those of the general population for people over age 60. During comparative analysis of morbidity rates between the groups (i.e., percentage of patients who suffer from a certain disease), we did not detect statistically significant allocation differences $(\mathrm{p} \geq$ 0.5 ). When analyzing the percentage of various diseases in each group, we detected several allocation anomalies. For example, the percentage of cardiovascular diseases was significantly higher in Group B compared to Group $\mathrm{C}(\mathrm{p} \leq 0.5)$, while the percentage of people with respiratory diseases in the same group was significantly higher compared to Group A $(\mathrm{p} \leq 0.5)$. The percentage of people who suffer from gastrointestinal diseases in Group B also turned out to be relatively higher compared to Group C $(p \leq 0.5)$. We believe such differences have arised from a comparatively small scope of selection, since the related values in the group, though different, did not differ from average ones in the population. The percentage of 
Table 1. Patients are assigned to groups by gender, age, associated pathology, and addiction to bad habits $(\mathrm{n}=1098)$

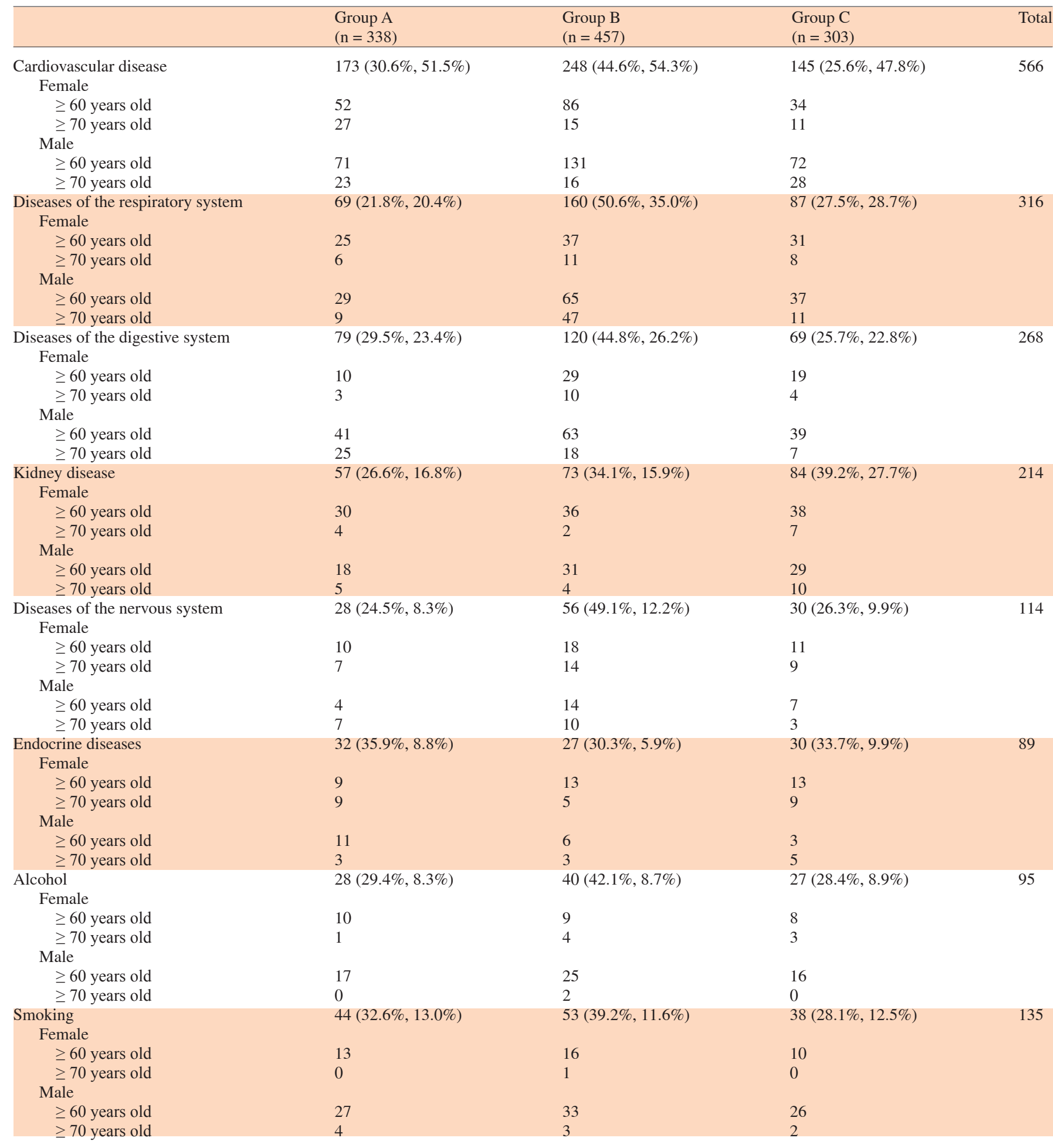

Group A: not taking caffeine or taking $\leq 100 \mathrm{mg} / \mathrm{d}$ caffeine $(\leq 1.5 \mathrm{mg} / \mathrm{kg})(1 \mathrm{cup}$ of coffee or 2 cups of tea or less $)$; Group B: taking 100-300 mg/d caffeine; Group C: taking $300 \mathrm{mg} / \mathrm{d}$ caffeine. At the moment of examination, all patients were in satisfactory condition. The sum of clinical entities (of particular diseases) may exceed the number of patients in a group. The data in brackets: 1-percentage of the total number of cases of a given disease; $2-$ percentage of number of patients in a group. 
Table 2. Distribution of patients of specific diseases

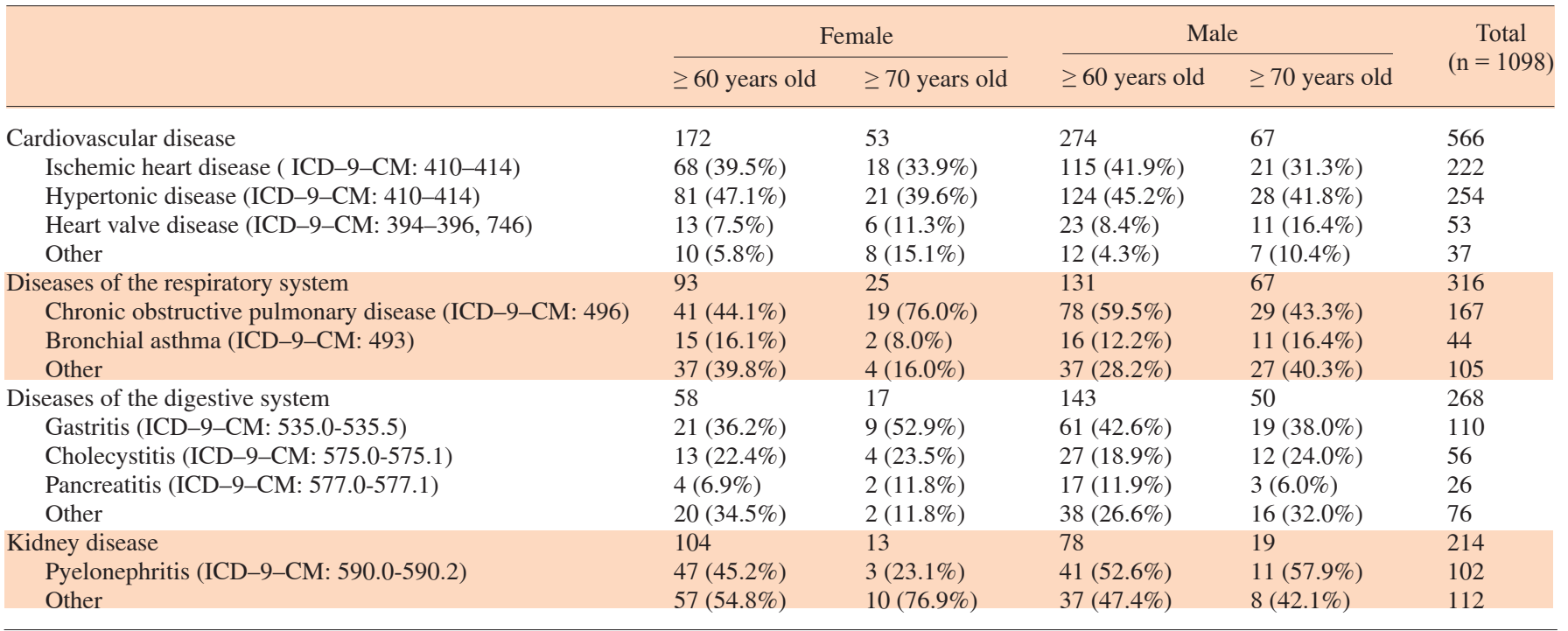

Table 3. Data from the OAB questionnaire, diaries of urination, and uroflowmetry $(\mathrm{n}=1,098)$

\begin{tabular}{llll}
\hline & Group A & Group B & Group C \\
\hline OAB-AT questionnaire (in scores) & & & \\
$\quad$ Daytime frequency & $1.3(0.4)$ & $1.3(1.0)$ & $4.2(0.7)^{* *}$ \\
$\quad$ Nighttime frequency & $1.5(0.7)$ & $1.7(1.4)$ & $1.9(0.8)$ \\
$\quad$ Urgency & $1.6(0.8)$ & $1.9(0.6)$ & $2.8(0.7)$ \\
$\quad$ Urgency incontinence & $0.6(0.5)$ & $0.5(0.5)$ & $0.8(0.8)$ \\
Diaries of urination (the number of & & & \\
episodes per day) & & & \\
$\quad$ Daytime frequency & $6.3(0.9)$ & $7.1(2.1)$ & $8.1(0.9)^{*}$ \\
$\quad$ Nighttime frequency & $0.9(0.6)$ & $1.1(0.6)$ & $1.5(0.7)$ \\
$\quad$ Episodes of Urgency & $0.3(0.2)$ & $0.3(0.3)$ & $0.9(0.3)^{*}$ \\
$\quad$ Episodes of incontinence & $0.1(0.1)$ & $0.1(0.1)$ & $0.3(0.2)$ \\
Uroflowmetry parameters & & & \\
$\quad \mathrm{Q}_{\text {aver }}$, ml/sec & $16.7(2.3)$ & $16.9(2.6)$ & $22.8(1.9)^{*}$ \\
$\mathrm{Q}_{\max }, \mathrm{ml} / \mathrm{sec}$ & $19.8(3.1)$ & $22.7(3.9)$ & $27.8(3.8)^{*}$ \\
\hline
\end{tabular}

Reduction in title urodynamic parameters. $\mathrm{Q}_{\text {aver }}$ : average flow rate; $\mathrm{Q}_{\max }$ : maximum flow rate. Standard deviation is indicated in parentheses; ignificance of differences $*<0.05 ; * *<0.01$.

moderate smokers and alcohol drinkers is also indicated in table 1 (recall that heavy smokers and drinkers were not allowed to participate in this study). Allocation of alcohol drinkers and smokers turned out to be correct, and significant differences between the groups were not detected. The total number of alcohol drinkers and moderate smokers turned out to be within ranges of $8.3-8.9 \%$ and $11.6-13.0 \%$, respectively, which is significantly lower than that of the general population, but is specific to this age group.

Table 2, which expands and specifies the previous one, presents detailed data about sporadic diseases in the patients examined. Hypertensive disease (39.6-47.1\%) and ischemic heart disease $(31.3-41.9 \%)$ are the most common among cardiovascular diseases. Chronic obstructive lung disease (43.3-76.0\%) was the most widespread among respiratory diseases while bronchial asthma was far less common (8.0-16.4\%). Gastritis was the most frequent among gastro-intestinal diseases (36.2-52.9\%); and pyelonephritis, among kidney diseases $(23.1-57.9 \%)$. The most frequent disease of the nervous system, as expected, was somatoform autonomic dysfunction. Diabetes was the most common endocrinopathy. The prevalence of specific diseases in the group researched was consistent, for the corresponding age of the 6 groups, with that of the population in whole.

After assigning patients to groups in accordance with the amount of caffeine intake, it was found that the percentage of patients with minimum and excessive caffeine doses was similar and amounted to $30.8 \%$ and $27.6 \%$, respectively. The share of patients whose daily caffeine dose exceeded $100 \mathrm{mg}$ but was below $300 \mathrm{mg}$ was $41.6 \%$. On the basis of examination performed, OAB was diagnosed in 396 patients $(36.1 \%)$. The number of patients with definite daily level of caffeine consumption, on the one hand, and presence of overactive bladder symptoms, on the other hand, are compared in fig. 2. 
OAB occurrence (whether non-existant, mild, or severe) was nearly identical between Groups A and B. The percentage of people without OAB signs were 69.2 and $68.0 \%$, respectively. Minimum symptoms and acute symptoms were detected in $20.1-20.4 \%$ and in 10.6$10.5 \%$ of patients, respectively. In Group C, composed of patients taking excessive amount of caffeine-containing drinks, the allocation was different. Almost half of patients from this group had symptoms of detrusor overactivity (weak in $28.0 \%$ of cases and severe in $20.1 \%$ of cases). The total number of patients with $\mathrm{OAB}$ symptoms in this group significantly differed from those in Groups $\mathrm{A}$ and $\mathrm{B}(\mathrm{p}<0.05)$.

The average value of several LUTS condition parameters in the patients examined is presented in table 3 . Regarding the analysis of the results of the OAB-AT questionnaire, a high level of daytime frequency of $4.2(0.7)$ points (significant difference from the results in Groups $\mathrm{A}$ and $\mathrm{B}, \mathrm{p}<0.01)$ stands out. Values of other parameters in Group $\mathrm{C}$ are also higher than those in Groups A and $\mathrm{B}$, sometimes with a strong trend (urgency), but not statistically significant. The results for Groups A and B have almost no differences. According to bladder diaries, values of daytime frequency in Group C significantly differ from those in Group A and are close to the values in Group B. The number of episodes of urgency in Group C significantly differs compared to the other 2 groups. The average volume velocity of urination in Group C is significantly higher than that in the other 2 groups. Thus, according to our data, a number of urodynamic parameters in people taking excessive doses of caffeine significantly differ compared to Groups A and B.

The criterion of involvement in the experiment was stable remission of chronic diseases of visceral organs for all participants. This allowed the selection of a group of patients that were unlikely taking drugs that inhibit or enhance cholinergic transmission, thus having impact on detrusor function. The analysis of patients' personal medical records carried out upon the completion of this study allowed us to determine if patients were taking M-cholinomimetic drugs during the experiment. M-anticholinergic drugs were used in 16 cases (1.4\%): atropini sulfas on a single occasion, during the diagnostic procedures when visiting the eye doctor in 5 patients; Extractum Belladonnae siccum, in 9 patients during combined treatment of gastroenterology disease; and the use of platyphyllini hydrotartras and methacinum reported in 2 cases. Comparing the time of taking these drugs to bladder diaries of specific patients showed that they did not have any significant effect on detrusor function. In

Caffeine: Risk of OAB Development of Elderly People addition, when carrying out the analysis of ratio between number of patients who were receiving any M-cholinoactive drugs during the experiment and total number of men and women who participated in this study, it was concluded that there was no significant effect of the drugs in this group on the condition of lower urinary tracts in the patients.

During the examination, $4(0.4 \%)$ patients stopped their participation due to a hypertonic crisis, $2(0.2 \%)$ patients due to acute exacerbation of chronic diseases, and $2(0.2 \%)$ patients due to reasons unrelated to their health condition.

\section{Discussion}

We have not found statistically significant differences in morbidity rate values between different groups (table 2 ). The same applies to the allocation of kidney and urinary tract diseases between the groups. Given this basis, we can conclude that various non-acute pathological conditions do not form any significant additional risk factor for progression of overactive bladder symptoms in patients who get different daily amount of caffeine. The results also show that the percentage of people consuming moderate amounts of alcohol or that smoke a few cigarettes every day is small in all 3 groups. Of course, this is due to experimental design, since our purpose was to minimize the impact of any other associated factors, except caffeine itself, on patients. Thus, people who consume excessive amount of liquid or diuretics, or heavy alcohol drinkers or smokers, were excluded from this study.

The effect of caffeine on OAB formation was studied previously [17-20]. In our study, we found that $1 / 3$ of people, both men and women over 60 years of age, who did not previously seek medical advice due to urination troubles, had signs of detrusor overactivity. These symptoms were moderate and did not bother patients too much in most cases $(63.4 \%)$. It was also found that most patients consume no more than $300 \mathrm{mg}$ of caffeine with drinks per day, and the percentage of these people suffering from $\mathrm{OAB}$ or severe detrusor overactivity were about $30 \%$ and $10 \%$, respectively. At the same time, the number of people suffering from $\mathrm{OAB}$ amounted to almost $50 \%$ among those taking more than $300 \mathrm{mg}$ caffeine per day. Additionally, the percentage of people suffering from detrusor overactivity was significantly higher among those taking excessive amounts of caffeine. 
At present, chemical and pharmacological properties of caffeine (1, 3, 7-3-methylxanthine) regarding the nervous system are considered to be thoroughly studied. Caffeine is known to increase reflex excitability of the spinal cord and also to decrease reabsorption of electrolytes in renal tubules which can aggravate enuresis [15-17]. Excessive stimulation of reticular formation by a large number of caffeine molecules may be one of the occurrence mechanisms of hyperactive detrusor symptoms. Another possible mechanism is higher formation and evacuation of secondary urine. Large additional urine volume leads to an increase in load on muscarinic receptors of the bladder. At a certain stage, "aging" bladder that suffers from a lack of functionally active muscarinic receptors loses its ability of adequate response to excessive urine volume, which is presented in urgency symptom occurrence, increase in urinary frequency, and in some cases, incontinence episodes.

Many researchers confirm the important role of diet in the emergence of OAB symptoms, while referring to an insufficient state of knowledge on the effect of such factors as caffeine, carbonated drinks, and artificial sweeteners [33]. However, there are also reports that indicate an increase of caffeine intake does not always result in overactivity symptoms, at least in people suffering from mental disorders [21]. A number of researchers caution against assumptions about the direct relation between caffeine intake and OAB formation [33, 34], but the majority of research results confirm the obvious effect of in- creased caffeine doses both on central nervous system's activity and OAB formation [15-17]. Data from most reports available from PubMed, PubMed Central, Scopus, and WoS databases conform to our results and confirm the information obtained by us concerning the importance of increased caffeine intake as a bladder overactivity formation factor in elderly people $[18,19]$.

In our study, we made an attempt to fully mitigate the possible impact of other agents on the functional activity of lower urinary tract by establishing caffeine as the only active dietary factor. In our opinion, we obtained sufficiently reliable evidence on its involvement in the $\mathrm{OAB}$ emergence process in elderly people.

We clearly realize that the study design has limited accuracy in counting the level of active material taken by patients. However, a considerable scope of sampling seems to partially mitigate this disadvantage. We believe that follow-up studies concerning caffeine effects on $\mathrm{OAB}$ formation and efficiency of minimizing its intake with overactive bladder symptoms are necessary.

\section{Conclusion}

A higher level of daily caffeine intake causes an increase in frequency of OAB symptoms and is likely to be a risk factor for $\mathrm{OAB}$ emergence. The average number of OAB symptoms in people who consume less caffeine per day does not differ from that in healthy people.

\section{References}

1 Lugo Salcedo F, Sánchez Borrego R: Assessment of female prevalence of overactive bladder $(\mathrm{OAB})$ in Barcelona using a self-administered screening questionnaire: the Cuestionario de Autoevaluación del Control de la Vejiga (CACV). Int Urogynecol J 2013; 24:1559-1566.

2 Wen JG, Li JS, Wang ZM, Huang CX, Shang XP, Su ZQ, Lu YT, Suo ZH, Wang Y, Qin GJ, Zhang WX, Heesakkers JP: The prevalence and risk factors of $\mathrm{OAB}$ in middle-aged and old people in China. Neurourol Urodyn 2014; 33:387-391.

3 Diamond P, Hassonah S, Alarab M, Lovatsis D, Drutz HP: The prevalence of detrusor overactivity amongst patients with symptoms of overactive bladder: a retrospective cohort study. Int Urogynecol J 2012;23:1577-1580.
4 Coyne KS, Sexton CC, Bell JA, Thompson CL, Dmochowski R, Bavendam T, Chen CI, Quentin Clemens J: The prevalence of lower urinary tract symptoms (LUTS) and overactive bladder $(\mathrm{OAB})$ by racial/ethnic group and age: results from OAB-POLL. Neurourol Urodyn 2013;32:230-237.

5 Heesakkers J, Cruz F, Igawa Y, Kocjancic E: Overactive bladder: pathophysiology, diagnostics, and therapies. Adv Urol 2011;2011: 863504 .

6 Wagg AS, Cardozo L, Chapple C, De Ridder D, Kelleher C, Kirby M, Milsom I, Vierhout M: Overactive bladder syndrome in older people. BJU Int 2007;99:502-509.

7 Andersson KE: Antimuscarinic mechanisms and the overactive detrusor: an update. Eur Urol 2011;59:377-386.
8 Andersson KE: Muscarinic acetylcholine receptors in the urinary tract. Handb Exp Pharmacol 2011;202:319-344.

9 Igawa Y, Aizawa N, Homma Y: Beta3-adrenoceptor agonists: possible role in the treatment of overactive bladder. Korean J Urol 2010;51: 811-818.

10 Kanai AJ: Afferent mechanism in the urinary tract. Handb Exp Pharmacol 2011;202:171205.

11 de Boer TA, Salvatore S, Cardozo L, Chapple C, Kelleher C, van Kerrebroeck P, Kirby MG, Koelbl H, Espuna-Pons M, Milsom I, Tubaro A, Wagg A, Vierhout ME: Pelvic organ prolapse and overactive bladder. Neurourol Urodyn 2010;29:30-39. 
12 Tyagi P, Tyagi V, Qu X, Lin HT, Kuo HC, Chuang YC, Chancellor M: Association of inflammaging (inflammation + aging) with higher prevalence of OAB in elderly population. Int Urol Nephrol 2014;46:871-877.

13 Zorba OÜ, Kırba S, Uzun H, Cetinkaya M, Önem K, Rifaio lu MM: Overactive bladder and pontine reticular formation. Urol Int 2013;91:417-422.

14 Sakakibara R, Panicker J, Fowler CJ, Tateno F, Kishi M, Tsuyusaki Y, Yamanishi T, Uchiyama T, Yamamoto T, Yano M: Is overactive bladder a brain disease? The pathophysiological role of cerebral white matter in the elderly. Int J Urol 2014;21:33-38.

15 Meeusen R, Roelands B, Spriet LL: Caffeine, exercise and the brain. Nestle Nutr Inst Workshop Ser 2013;76:1-12.

16 Haller S, Montandon M, Rodriguez C: Acute caffeine administration effect on brain activation patterns in mild cognitive impairment. J Alzheimers Dis 2014;41:101-112.

17 Lohsiriwat S, Hirunsai M, Chaiyaprasithi B: Effect of caffeine on bladder function in patients with overactive bladder symptoms. Urol Ann 2011;3:14-18.

18 Kershen R, Mann-Gow T, Yared J, Stromberg I, Zvara P: Caffeine ingestion causes detrusor overactivity and afferent nerve excitation in mice. J Urol 2012;188:1986-1992.

19 Maserejian NN, Wager CG, Giovannucci EL, Curto TM, McVary KT, McKinlay JB: Intake of caffeinated, carbonated, or citrus beverage types and development of lower urinary tract symptoms in men and women. Am J Epidemiol 2013;177:1399-1410.
20 Wells MJ, Jamieson K, Markham TC, Green SM, Fader MJ: The effect of caffeinated versus decaffeinated drinks on overactive bladder: a double-blind, randomized, crossover study. J Wound Ostomy Continence Nurs 2014;41:371-378.

21 Chakravarthy V, Tolbert M, Garcia C, Miller $\mathrm{J}$ : Overactive bladder and caffeine: comparing women with and without mental health diagnoses. Int J Urol Nurs 2010;4:13-21.

22 Coyne KS, Zyczynski T, Margolis MK, Elinoff V, Roberts RG: Validation of an overactive bladder awareness tool for use in primary care settings. Adv Ther 2005;22:381394.

23 Coyne KS, Margolis MK, Bavendam T, Roberts R, Elinoff V: Validation of a 3-item OAB awareness tool. Int J Clin Pract 2011;65:219224.

24 Parsons M, Amundsen CL, Cardozo L, Vella M, Webster GD, Coats AC: Bladder diary patterns in detrusor overactivity and urodynamic stress incontinence. Neurourol Urodyn 2007;26:800-806.

25 Amundsen CL, Parsons M, Cardozo L, Vella M, Webster GD, Coats AC: Bladder diary volume per void measurements in detrusor overactivity. J Urol 2006;176:2530-2534.

26 Schröder A, Abrams P, Andersson KE, Artibani W, Chapple CR, Drake MJ, Hampel C, Neisius A, Tubaro A, Thüroff JW: Guidelines on Urinary Incontinence. European Association of Urology, 2009, S52.
27 Singh G, Lucas M, Dolan L, Knight S, Ramage $\mathrm{C}$, Hobson PT: Minimum standards for urodynamic practice in the UK. Neurourol Urodyn 2010;29:1365-1372.

28 Dmochowski RR, Larson-Peters A, Aronstein WS, Seifu Y: Efficacy of Darifenacin in patients with varying baseline symptom severity. UroToday Int J 2009;2(3).

29 Wagg A: Treating overactive bladder in the elderly. Can Urol Assoc J 2011;5(5 Suppl 2): S149-S151.

30 Cano-Marquina A, Tarín JJ, Cano A: The impact of coffee on health. Maturitas 2013;75: $7-21$.

31 Juliano LM, Griffiths RR: Caffeine; in Lowinson JH, Ruiz P, Millman RB, Langrod JG (eds.). Substance Abuse: A Comprehensive Textbook, ed 4. Baltimore, Lippincott, Williams, \& Wilkins, 2005, pp403-421.

32 National Institute on Alcohol Abuse and Alcoholism No.16 PH 315 April 1992.

33 Robinson D, Giarenis I, Cardozo L: You are what you eat: the impact of diet on overactive bladder and lower urinary tract symptoms. Maturitas 2014;79:8-13.

34 Selo-Ojeme D, Pathak S, Aziz A, Odumosu M: Fluid and caffeine intake and urinary symptoms in the UK. Int J Gynaecol Obstet 2013;122:159-160. 